\title{
Exocrine Pancreas Cancer and Thromboembolic Events: A Systematic Literature Review
}

\author{
Andrew S. Epstein, MD, and Eileen M. O'Reilly, MD
}

\begin{abstract}
Exocrine pancreas cancer continues to represent a significant therapeutic challenge, with high rates of mortality and morbidity, including from thromboembolic events, which have long been described as a frequent complication of the disease. This article provides a systematic and comprehensive review of the literature to address the clinical and pathologic features recognized in pancreas cancer pertaining to thrombosis, and to discuss ongoing investigations of prophylactic anticoagulation in the hopes of improving disease-related outcomes. (JNCCN 2012;10:835-846)
\end{abstract}

\section{Medscape: Continuing Medical Education Online}

\section{Accreditation Statement}

This activity has been planned and implemented in accordance with the Essential Areas and policies of the Accreditation Council for Continuing Medical Education through the joint sponsorship of Medscape, LLC and JNCCN - The Journal of the National Comprehensive Cancer Network. Medscape, LLC is accredited by the ACCME to provide continuing medical education for physicians.

\footnotetext{
Medscape Medscape, LLC designates this Journal-based CME activity for a maximum of 1.0 AMA PRA Category 1 Credit(s) ${ }^{\mathrm{TM}}$. Physicians should claim only the credit commensurate with the extent of their participation in the activity.
}

From Memorial Sloan-Kettering Cancer Center, New York, New York. Submitted June 26, 2011; accepted for publication December 2, 2011. Correspondence: Eileen M. O’Reilly, MD, Memorial Sloan-Kettering Cancer Center, 300 East 66th Street, New York, NY 10065.

E-mail: oreillye@mskcc.org

\section{EDITOR}

Kerrin M. Green, MA

Assistant Managing Editor, Journal of the National Comprehensive Cancer Network

Disclosure: Kerrin M. Green, MA, has disclosed no relevant financial relationships.
All other clinicians completing this activity will be issued a certificate of participation. To participate in this journal CME activity: (1) review the learning objectives and author disclosures; (2) study the education content; (3) take the post-test with a $70 \%$ minimum passing score and complete the evaluation at www.medscape. org/journal/jnccn; (4) view/print certificate.

Release date: July 7, 2012; Expiration date: July 7, 2013.

\section{Learning Objectives}

Upon completion of this activity, participants will be able to:

- Distinguish risk factors for thromboembolism among patients with pancreatic cancer

- Analyze recommendations for primary prophylaxis against thromboembolism among patients with pancreatic cancer

- Assess the best treatment for thromboembolism among patients with pancreatic cancer

- Evaluate outcomes improved with treatment of thromboembolism among patients with pancreatic cancer

Malignancy is a well-established risk factor for the development of venous thromboembolic events, both in hospitalized and ambulatory patients. Venous thromboembolic events are a major contributor to cancer- and treatment-related morbidity and mortality. Exocrine pancreas cancer is one of the most common malignancies associated with thrombosis, with most modern studies reporting incidence ranging from $5 \%$ to $27 \% .{ }^{1-6}$

\section{AUTHORS AND CREDENTIALS}

Andrew S. Epstein, MD, Memorial Sloan-Kettering Cancer Center, New York, New York

Disclosure: Andrew S. Epstein, MD, has disclosed no relevant financial relationships.

Eileen M. O'Reilly, MD, Memorial Sloan-Kettering Cancer Center, New York, New York

Disclosure: Eileen M. O'Reilly, MD, has disclosed no relevant financial relationships.

\section{CME AUTHOR}

Charles P. Vega, MD, Health Sciences Clinical Professor; Residency Director, Department of Family Medicine, University of California, Irvine Disclosure: Charles P. Vega, MD, has disclosed no relevant financial relationships. 
Epstein and O’Reilly

Various patient-, treatment-, and increasingly recognized pancreas tumor-related factors contribute to thrombosis (Table 1). Additionally, venous thromboembolic events have been found to portend a poorer prognosis in patients with pancreas cancer, ${ }^{3}$ and have been implicated in early deaths after diagnosis. ${ }^{7}$ Patients with various cancers diagnosed within 1 year of a thrombosis often have more extensive malignancy and worse outcome. ${ }^{8}$ This association between thrombosis and shorter survival has been validated in a prospective case-control study by Mandala et al. ${ }^{9}$ Anticoagulants may have treatment effects on the malignancy. ${ }^{10,11}$

Pancreas cancer is notoriously difficult to treat, and current chemotherapy regimens offer only modest disease control. Therefore, new therapies are clearly needed in hopes of impacting survival and treatment- and disease-related morbidity, including that from thrombosis. Although both superficial thrombophlebitis and arterial thromboses, such as myocardial infarction and stroke, have been well described in pancreas cancer, this article focuses on deep venous thromboses (hereafter referred to as

\section{Table 1 Selected Factors Relevant to Pancreas Cancer and Thrombosis}

\section{Molecular Associations}

Tissue factor ${ }^{36,42}$

Thrombomodulin ${ }^{34}$

Thrombin ${ }^{35}$

Thrombin-antithrombin III complex ${ }^{36}$

Plasminogen activator inhibitor-1 $1^{37}$

Platelet factor $4^{38}$

Fibrin $^{40}$

Tissue factor pathway inhibitor ${ }^{41}$

Clinical and Treatment Variables

Hospitalization/sedentary status

Surgery

Venous access/catheterization

Weight extremes ${ }^{14,21}$

Blood type group $\mathrm{A}^{22}$

Leukocytosis $^{13,14}$

Anemia ${ }^{13,14}$

Thrombocytosis ${ }^{13,14}$

Medications (erythropoietin-stimulating agents, ${ }^{13,14}$ chemotherapy, ${ }^{31-33}$ megestrol ${ }^{86}$ )

Comorbidities (heart, liver, and kidney disease; diabetes) thrombosis), because these predominate. The clinical and molecular underpinnings of thrombosis in patients with cancer are first discussed, highlighting key studies performed not only in pancreas cancer but also in other tumor types.

\section{Methods}

After an initial query of PubMed for literature on pancreas cancer and thrombosis, and in collaboration with the authors' institution's library staff, a comprehensive search was performed of articles contained in 5 databases (PubMed, Embase, Web of Science/ Science Citation Index, Scopus, and Cochrane) involving the key words (and associated subterms) pancreas cancer, anticoagulation, and thrombosis. From a search yield of 1895 results, articles chosen for inclusion herein predominantly consisted of original studies on preclinical pathophysiology or clinical trials regarding thrombosis primary or secondary prophylaxis in patients with pancreas cancer. Articles outside of this purview were excluded.

\section{Patient-Related Risk Factors for Thrombosis}

The 1860s saw the description of Virchow's triad and the first association between thrombosis and malignancy by Trousseau. ${ }^{12}$ Since then, numerous clinical variables have been shown to either contribute to or be associated with thrombogenicity, and many have been studied in the cancer population, specifically in patients with pancreas cancer. Prediction tools have been created for the risk assessment and stratification of patients undergoing cancer treatment. ${ }^{13-16}$ Khorana et al. ${ }^{14}$ developed and validated their model, which showed an association between thrombosis and the following 5 clinical factors: cancer site (for which pancreas was deemed a very high-risk site); platelet count $350,000 / \mathrm{L}$ or greater; hemoglobin less than $10 \mathrm{~g} / \mathrm{dL}$ (and/or use of erythropoietin-stimulating agents); leukocyte count greater than 11,000/L; and body mass index of $35 \mathrm{~kg} / \mathrm{m}^{2}$ or greater. Ay et al. ${ }^{17}$ used these factors and also incorporated the biomarkers soluble P-selectin and D-dimer.

Thrombosis in cancer has also been explored outside of the above prediction models, including in hospitalized patients with neutropenia. ${ }^{18}$ Analysis of the Vienna Cancer and Thrombosis Study, published in 
2010, illustrated high platelet count as an independent predictor of thrombosis, ${ }^{19}$ a correlation originally noted by Khorana et al. ${ }^{14} \mathrm{~A}$ recent abstract ${ }^{20}$ showed that albumin level may independently predict for the development of thrombosis. Finally, patient weight, particularly obesity, has also been studied and identified to be a potential risk factor for thrombosis in patients with cancer. In pancreas cancer, Greenblatt et al. ${ }^{21}$ recently showed that both underweight and obesity were associated with more venous thrombosis and worse overall survival after pancreas resection.

An interesting clinical observation regarding thrombosis risk specifically in pancreas cancer relates to blood type. In a retrospective review of institutionally treated patients with pancreas cancer, thromboses were significantly more common not only in patients with metastatic disease but also in those with $\mathrm{A}$ versus non-A blood type (odds ratio [OR], 3.0; 95\% CI, 1.4-6.6; $P=.005) .{ }^{22}$

\section{Molecular Risk Factors for Thrombosis}

The molecular underpinnings of thrombosis in malignancy have been extensively investigated. The myriad details of this relationship are beyond the scope of this review (although explored more fully in the "PancreasSpecific Molecular Risk Factors for Thrombosis" section), but key components include tumor cell interactions with endothelium, platelets, and leukocytes; cytokine release; and the dual upregulation of procoagulant molecules along with downregulation of anticoagulant molecules. Investigations of molecular predictors for thrombosis have been performed recently and included patients with pancreas cancer. The Vienna Cancer and Thrombosis Study prospectively analyzed factors associated with the risk of thrombosis in 821 patients with various newly diagnosed malignancies or with disease progression and not actively undergoing treatment. ${ }^{23}$ Elevated levels of D-dimer and prothrombin fragment 1 and 2 were independent predictors for the development of thrombosis. The same group also prospectively showed soluble P-selectin to be an independent predictor of thrombosis. ${ }^{24}$ Finally, the group also found that thrombin generation increased the risk of venous thrombosis. ${ }^{25}$

\section{Treatment-Related Risk Factors for Thrombosis}

Associations between thrombosis and various treatments, including surgery, central venous catheters, and hospitalization, are well documented in the medical literature. ${ }^{26-28}$ Erythropoietin-stimulating agent use has declined sharply in the past few years given the growing knowledge about thrombogenicity and worsened survival. ${ }^{29,30}$ Chemotherapy in pancreas cancer also increases thrombogenicity, including the commonly used agent gemcitabine. ${ }^{31,32}$ Thrombosis occurred in $18.1 \%$ of 932 patients with various malignancies treated with a cisplatin-containing regimen in 2008 at Memorial Sloan-Kettering Cancer Center. ${ }^{33}$ The most common cancer associated with thrombosis was pancreas cancer (representing $8.5 \%$ of the cohort), which occurred in $36.7 \%$ of the patients.

\section{Pancreas-Specific Molecular Risk Factors for Thrombosis}

Investigators have shown the interaction between many procoagulant and fibrinolysis molecules and the development and activity of pancreas cancer, both in cell lines and in vivo. These observations underlie the notion that prophylactic anticoagulation in patients with pancreas cancer may exert a therapeutic benefit. These molecules include thrombomodulin, ${ }^{34}$ thrombin, ${ }^{35}$ thrombin-antithrombin III complex, ${ }^{36}$ plasminogen activator inhibitor- 1,37 platelet factor $4,^{38} \mathrm{P}$-selectin glycoprotein ligand $1,{ }^{39}$ fibrin, ${ }^{40}$ and tissue factor pathway inhibitor, ${ }^{41}$ with the most attention focused on the role of tissue factor ${ }^{42}$ (both soluble and cell membrane-bound ${ }^{36}$ ) in pancreas carcinogenesis, and related thrombogenicity. Delluc et $a .^{43}$ observed higher levels of tissue factor in patients with pancreas cancer and thrombosis than in those with non-pancreas cancers and thrombosis or with idiopathic thrombosis.

Tissue factor has also been shown to enable procoagulant activity through microparticles released from cells both in vivo and in vitro, ${ }^{44}$ including in a pancreas cancer cell line, ${ }^{45}$ and these tissue factorbearing microparticles have been shown to be present in higher amounts in patients with thrombosis and cancer than in those with idiopathic thrombosis without cancer or those with cancer without thrombosis. ${ }^{46}$ 
Epstein and O’Reilly

\section{Anticoagulation in Solid Malignancies}

Numerous anticoagulation trials have been conducted in solid malignancies, with a survival benefit suggested in several trials, especially in patients with limited-stage small cell lung cancer with no history of thrombosis. ${ }^{47}$ The suggestion of possible benefit of anticoagulation in the survival outcome of patients with cancer stems from both primary and secondary prophylaxis trials. Numerous secondary prophylaxis studies have been conducted wherein patient outcomes are analyzed in subgroups of the larger trial population. Moreover, primary end points in these trials address thrombosis-specific factors, such as thrombosis recurrence, whereas survival-related outcomes serve as secondary end points. With these caveats in mind, randomized controlled trials and meta-analyses of these trials have reported survival benefits in cancer patients randomized to low-molecular-weight heparin compared with vitamin $\mathrm{K}$ antagonists and unfractionated heparin. Low-molecular-weight heparin has been postulated to directly influence tumor growth, angiogenesis, and metastasis, which are effects thought not to be exerted by vitamin $\mathrm{K}$ antagonists or unfractionated heparin.

One of the most noted secondary thromboprophylaxis randomized controlled trials compared thrombosis treatment with 6 months of dalteparin versus a vitamin $\mathrm{K}$ antagonist. ${ }^{48}$ The primary end point was recurrent venous thrombosis, which occurred significantly less in patients receiving dalteparin. Although no difference in survival was seen between the treatment arms, a post hoc subgroup analysis of the patients with localized cancer yielded a 12 -month all-cause mortality of $35 \%$ in the vitamin $\mathrm{K}$ antagonist group versus $20 \%$ in the dalteparin group $(P=0.04)$. In patients with metastatic cancer, no survival difference was reported $(69 \%$ and $72 \%$, respectively, for patients with a vitamin $\mathrm{K}$ antagonist and dalteparin; $P=.46) .{ }^{49}$ Compared with unfractionated heparin, meta-analyses suggest survival improvements in patients treated with low-molecular-weight heparin. ${ }^{50-53}$

Regarding primary thromboprophylaxis, small cell lung cancer has been perhaps the most extensively studied solid tumor type, ${ }^{54-58}$ and in some of these trials, a statistically significant benefit in time to progression and/or survival with anticoagulation has been seen in these patients, including with warfarin, ${ }^{54}$ unfractionated heparin, ${ }^{56}$ and low-molecular- weight heparin. ${ }^{58}$ In the low-molecular-weight heparin and unfractionated heparin trials, the benefit was more pronounced in patients with limited-stage disease, but was also statistically significant in patients with advanced small cell lung cancer. These trials should, however, be interpreted in the context of limited sample sizes, incompletely reported complication and performance status data, heterogeneous patient populations, and varying anticoagulant doses.

The results of more recent primary thromboprophylaxis controlled trials of low-molecular-weight heparin in non-small cell lung cancer tumor types have been mixed. ${ }^{59-61}$ Several meta-analyses have set out to clarify the degree of anticoagulant effect on patient survival, although details of these trials ${ }^{62-64}$ are outside the scope of this review.

Further randomized controlled trials are needed to clarify this possible antineoplastic benefit, which also must be weighed against cost and bleeding risk before anticoagulants are routinely implemented for primary prophylaxis. ${ }^{63,65}$ Alternatives to conventional anticoagulants are also deserving of further investigation. One trial (ClinicalTrials.gov identifier: NCT01020006) is currently investigating a factor VIIa inhibitor in patients with advanced pancreas cancer. Additionally, statin use has been associated with lower thrombosis risk in retrospective studies, ${ }^{66,67}$ possibly because of lipid-mediated platelet activation and endothelial disruption.

\section{Incidence and Effect of Thrombosis in Pancreas Cancer}

Sproul ${ }^{68}$ has been credited with first fully describing the association of thrombosis and pancreas cancer in 1938 , reporting a frequency of $30 \%$ in a large consecutive autopsy series of 4258 cases (of which 47 patients had pancreas cancer). Since then, multiple reports have followed, firmly establishing this observation. Table 2 details these pancreas cancer-specific cohorts. Autopsy series of pancreas cancer, in particular, have consistently shown the commonality of thrombosis (pulmonary embolism specifically in one study ${ }^{69}: 42 \%$ ), ranging from $19 \%$ to $67 \%$ of all cases. ${ }^{70-74}$ In recent decades, far fewer reports use autopsy methodology, and instead describe the incidence of thrombosis diagnosis in living patients clinically. Worldwide, a Dutch center examined thrombosis rates in 202 patients with pancreas cancer from 1990 to 2000, ${ }^{1}$ showing a more than 
Pancreas Cancer and Thrombosis

\begin{tabular}{|c|c|c|c|c|}
\hline Reference & $\mathbf{N}$ & Study Type & $\%^{a}$ & Notes \\
\hline $\begin{array}{l}\text { Cubilla and Fitzgerald, }{ }^{2} \\
1978\end{array}$ & 380 & Retrospective & 14 & $\begin{array}{l}\text { Histologically confirmed patients at MSKCC }{ }^{b} \text { from } \\
\text { 1949-1972 }\end{array}$ \\
\hline Pinzon et al., ${ }^{5} 1986$ & 130 & Retrospective & 6.9 & $\begin{array}{l}\text { Consecutive patients at MDACC; mucin production } \\
\text { and body/tail location associated with thrombosis }\end{array}$ \\
\hline Mandala et al., ${ }^{3} 2007$ & 227 & Retrospective & 26 & $\begin{array}{l}\text { Patients with unresectable pancreas cancer in } 3 \\
\text { clinical trials }\end{array}$ \\
\hline Mitry et al., ${ }^{6} 2007$ & 90 & Retrospective & 27 & $\begin{array}{l}\text { No survival differences between patients with and } \\
\text { without thrombosis }\end{array}$ \\
\hline Oh et al., ${ }^{4} 2008$ & 75 & Retrospective & 5 & $\begin{array}{l}\text { Korean authors suggest possible ethnobiologic } \\
\text { factors in relatively low incidence }\end{array}$ \\
\hline Epstein et al., ${ }^{75} 2011$ & 1915 & Retrospective & 36 & $\begin{array}{l}\text { Patients with pancreas cancer at MSKCC receiving } \\
\text { chemotherapy }\end{array}$ \\
\hline Mikal et al., ${ }^{70} 1950$ & 100 & $\begin{array}{l}\text { Autopsy } \\
\text { series }\end{array}$ & 67 & $18 \%$ in head of pancreas, $49 \%$ in body/tail \\
\hline Thompson et al.., 1952 & 157 & $\begin{array}{l}\text { Autopsy } \\
\text { series }\end{array}$ & 31 & $\begin{array}{l}25 \text { single thromboses, } 23 \text { patients with multiple } \\
\text { thromboses }\end{array}$ \\
\hline $\begin{array}{l}\text { Soederstroem and } \\
\text { Bjersing, }^{72} 1963\end{array}$ & 50 & $\begin{array}{l}\text { Autopsy } \\
\text { series }\end{array}$ & 52 & $\begin{array}{l}\text { Included anatomy: inferior vena cava, pelvic and } \\
\text { thigh veins }\end{array}$ \\
\hline Lowe and Palmer, ${ }^{74} 1967$ & 100 & $\begin{array}{l}\text { Autopsy } \\
\text { series }\end{array}$ & 29 & $8 \%$ clinical, $21 \%$ autopsy \\
\hline Mao et al., ${ }^{73} 1995$ & 154 & $\begin{array}{l}\text { Autopsy } \\
\text { series }\end{array}$ & 19.4 & $\begin{array}{l}\text { Consecutive autopsies at } 3 \text { affiliated Ohio teaching } \\
\text { hospitals }\end{array}$ \\
\hline Blom et al., ${ }^{1} 2006$ & 202 & Prospective & $108.3^{b}$ & $\begin{array}{l}\text { Increased risk with body/tail tumors, chemotherapy, } \\
\text { surgery, and metastatic disease }\end{array}$ \\
\hline
\end{tabular}

Abbreviations: MDACC, MD Anderson Cancer Center; MSKCC, Memorial Sloan-Kettering Cancer Center. aPercentage incidence figures are relative to the individual specific study periods.

bIn 1000 patient years.

50-fold increase compared with the general population. The most recently reported single-institution review actually reported a relatively low thrombosis incidence of $5 \%$ in 75 Korean patients with pancreas cancer, suggesting a possible ethnicity effect. ${ }^{4}$

At Memorial Sloan-Kettering Cancer Center, in 1915 patients receiving chemotherapy from January 1, 2000, through December 31, 2009, 36\% had been diagnosis-coded with a thrombosis and confirmed by chart review. ${ }^{75}$ The investigators found that thrombosis was correlated with significantly worse overall survival in these patients (hazard ratio [HR], 2.6;95\% CI, 2.3-2.8; $P<.01$ ), particularly early thromboses (HR, $2.1 ; 95 \% \mathrm{CI}, 1.7-2.5 ; P<.01$ vs. late or no thrombosis). Early thromboses were defined as those diagnosed before, or up to 1.5 months after, a pancreas cancer diagnosis. The interaction between any thrombosis and survival outcome in pancreas cancer was shown in a previous report on 227 patients with advanced disease. ${ }^{3}$ However, a more recent retrospective review of 201 patients with pancreas cancer reported no statis- tical difference in survival between patients with and without thromboses $(P=.9) \cdot{ }^{76}$ Moreover, the effect of early thrombosis timing on pancreas cancer-specific survival has never been reported.

\section{Anticoagulation in Pancreas Cancer}

Given the urgent need for improvements in pancreas cancer therapeutics, studies have been performed examining the role of primary thromboprophylaxis. Investigations reported thus far, some only at an early analysis time point ${ }^{77}$ and not all solely in patients with pancreas cancer, ${ }^{78}$ show a reduction in thromboembolic events, ${ }^{79}$ and some even suggest improvements in time to progression and overall survival. .0,81 $^{8}$ However, a more recent trial, albeit also not solely in patients with pancreas cancer, did not show a difference in time to progression or overall survival. ${ }^{82}$

Although the use of newer-generation heparins has recently been reported in the adult oncology setting, and despite the fact that oral anticoagulants 
Epstein and O'Reilly

(e.g., direct thrombin inhibitors and factor Xa inhibitors) have actively been studied recently in the noncancer population, a strong foundation of evidence nevertheless supports low-molecular-weight heparin over vitamin $\mathrm{K}$ antagonists in the initial and longterm management of thrombosis in patients with cancer. ${ }^{83}$ Therefore, recent anticoagulation studies in the pancreas cancer population primarily use lowmolecular-weight heparin. Most studies have evaluated symptomatic peripheral thromboses, although a retrospective study by Price et al. ${ }^{84}$ of patients with pancreas cancer with portal vein thromboses suggested that survival may be increased with anticoagulation. These results must be interpreted in the context of the study's retrospective design and the lack of randomized trials of anticoagulation for portal vein thromboses. For portal vein thromboses, individual patient factors must be taken into account, such as acuity of the event, bleeding risk, and presence of underlying liver disease.

The following sections discuss trials involving anticoagulants in pancreas cancer. Methodology, anticoagulant, and tumor type are key differences to be noted across these investigations. Table 3 includes pancreas cancer-specific randomized trials, including those with results yet to be reported.

\section{Retrospective Studies}

A German group reported provocative results in a retrospective analysis of 240 patients with advanced pancreas adenocarcinoma treated with chemotherapy. ${ }^{81}$ Of the 213 patients on whom documentation was available, 94 had received low-molecular-weight heparin (specific doses were not indicated; patients either received prophylactic-dose certoparin $[\mathrm{n}=$ 39], prophylactic-dose dalteparin [ $\mathrm{n}=50]$, or therapeutic dose nadroparin $[n=5])$. Overall survival was measured as time from initiation of chemotherapy to death and was found to not vary significantly, depending on whether low-molecular-weight heparin was administered. However, when dividing their population into metastatic and locally advanced pancreas cancer, the investigators observed a statistically significant effect of low-molecular-weight heparin on the survival of patients with metastatic disease (6.6 and 3.8 months, respectively, for the low-molecularweight heparin group and the non-low-molecularweight heparin group; HR, 0.6; 95\% CI, 0.4-0.8; $P=.006)$. As the authors conclude, this retrospective analysis requires prospective validation.

\section{Prospective, Nonrandomized Studies}

A Turkish group examined a similar question in a prospective, albeit nonrandomized design. ${ }^{80}$ They treated 69 patients with advanced pancreas cancer with a combination of gemcitabine and cisplatin with $(\mathrm{n}=35)$ or without $(\mathrm{n}=34)$ the addition of the low-molecular-weight heparin nadroparin (2850 $\mathrm{IU} / \mathrm{d})$. Patients who received low-molecular-weight heparin did so in the context of prospective evaluation, whereas the group receiving chemotherapy alone were patients previously treated with the same regimen, and their outcomes were analyzed retrospectively. Patients were matched equally in terms extent of disease. The nadroparin group had longer time to progression and overall survival compared with the chemotherapy-alone group (7.3 vs. 4.0 months; $P=.0001 ; 13.0$ vs. 5.5 months; $P=.0001$ ). Toxicity was similar in both groups, and specifically no treatment-related bleeding complications were seen in the nadroparin group. No statistically significant difference in thrombosis was seen between the groups, suggesting an alternate mechanism for low-molecular-weight heparin benefit. Nonetheless, these results must be considered in the context of the nonrandomized study design and small sample size.

Although the above investigations used lowmolecular-weight heparin primary prophylaxis, low-dose $(1.25 \mathrm{mg} / \mathrm{d})$ warfarin has been tested by Nakchbandi et al..$^{85}$ Their sample size of 17 patients was very small, however. This and other methodologic concerns limit the applicability of warfarin as a therapeutic strategy in this setting.

\section{Prospective, Randomized Studies (Not Pancreas Cancer-Specific)}

Agnelli et al..$^{78}$ published a randomized placebo-controlled trial of nadroparin for primary thromboprophylaxis in patients of broad solid tumor types receiving systemic chemotherapy for advanced disease. In a 2:1 ratio, the patients included in the analyses received nadroparin $(n=769)$ or placebo $(n=381)$ for the duration of chemotherapy, up to a maximum of 4 months. The study's primary end point was symptomatic venous or arterial thromboembolic events. Of the patients in the nadroparin arm, $2.0 \%$ versus $3.9 \%$ treated with placebo experienced a thromboembolic event $(P=.02)$. No significant difference in major or minor bleeding episodes was seen between the arms. van Doormaal et al. ${ }^{82}$ also investigated primary prophylaxis nadroparin in a co- 
Pancreas Cancer and Thrombosis

\begin{tabular}{|c|c|c|c|c|c|}
\hline Reference & $\mathbf{N}$ & Drug & Chemotherapy & Median Survival & Notes \\
\hline Maraveyas et al., ${ }^{77} 2009$ & 123 & Dalteparin & Gemcitabine & $\begin{array}{l}\text { Lethal thrombosis } \\
\text { and sudden death, } \\
0 \% \text { in dalteparin } \\
\text { arm vs. } 9 \% \text { in } \\
\text { control }(P=.028) \text {; } \\
\text { but "early death } \\
\text { burden," } 7 \% \text { vs. } \\
11 \%(P=.62) . \text { No } \\
\text { overall survival } \\
\text { difference }\end{array}$ & $\begin{array}{l}\text { Reduction in } \\
\text { primary end point of } \\
\text { thrombosis ( } 25 \% \text { to } \\
3.5 \% \text { over first } 100 \mathrm{~d} \text {; } \\
31 \% \text { to } 12 \% \text { overall) }\end{array}$ \\
\hline Riess et al., ${ }^{79} 2010$ & 312 & Enoxaparin & $\begin{array}{l}\text { Gemcitabine- } \\
\text { based (+/- 5FU/ } \\
\text { cisplatin } \\
\text { depending on } \\
\text { performance } \\
\text { status) }\end{array}$ & $\begin{array}{l}8 \text { mo without } \\
\text { enoxaparin, } \\
8.3 \text { mo with } \\
\text { enoxaparin } \\
(P=.501) \text {; median } \\
\text { follow-up time of } \\
45 \text { mo }\end{array}$ & $\begin{array}{l}\text { Closed early because } \\
\text { of significant } \\
\text { symptomatic } \\
\text { thromboembolism } \\
\text { reduction } 9.9 \% \text { vs. } \\
1.3 \% \text { at } 3 \text { mo (primary } \\
\text { end point); at } 12 \text { mo: } \\
15.1 \% \text { vs. } 5.0 \%\end{array}$ \\
\hline NCT00031837a & 400 & Dalteparin & $\begin{array}{l}\text { Systemic } \\
\text { gemcitabine }\end{array}$ & $\begin{array}{l}\text { Pending } \\
\text { (secondary end } \\
\text { point) }\end{array}$ & $\begin{array}{l}\text { Pending results, } \\
\text { primary end point is } \\
\text { quality of life }\end{array}$ \\
\hline NCT00662688 & 136 & Dalteparin & $\begin{array}{l}\text { Gemcitabine +/- } \\
\text { capecitabine }\end{array}$ & $\begin{array}{l}\text { Pending } \\
\text { (secondary end } \\
\text { point) }\end{array}$ & $\begin{array}{l}\text { Pending results, } \\
\text { primary end point } \\
\text { is thromboembolic } \\
\text { event rate }\end{array}$ \\
\hline NCT00966277a & 87 & Dalteparin & $\begin{array}{l}\text { Investigator } \\
\text { choice }\end{array}$ & $\begin{array}{l}\text { Pending } \\
\text { (secondary end } \\
\text { point) }\end{array}$ & $\begin{array}{l}\text { Pending results, } \\
\text { primary end point } \\
\text { is thromboembolic } \\
\text { event rate }\end{array}$ \\
\hline
\end{tabular}

${ }^{a}$ ClinicalTrials.gov identifier.

hort of patients with different malignancies, albeit in a more limited number of histologies. In this openlabel, uncontrolled randomized protocol assessing safety and survival, 244 patients received nadroparin (weight-adjusted therapeutic doses for 2 weeks followed by half-therapeutic doses for an additional 4 weeks) versus no nadroparin $(\mathrm{n}=259)$. Patients had either hormone-refractory prostate cancer, nonsmall cell lung cancer, or locally advanced pancreas cancer. No difference was observed in bleeding, time to progression, or overall survival. The median survival was 13.1 months in the nadroparin arm versus 11.9 months in the no-nadroparin arm (HR, 0.94; 95\% CI, 0.75-1.18, adjusted for cancer type).

\section{Prospective, Randomized Studies (Pancreas Cancer-Specific)}

In 2009, an abstract by Maraveyas et al..$^{77}$ presented results of their phase IIb FRAGEM (Fragmin and Gemcitabine) trial, wherein patients with advanced pancreas cancer were randomized to gemcitabine or gemcitabine with therapeutic-dose, primary prophylaxis dalteparin given for 12 weeks (200 IU/kg daily for 4 weeks, then $150 \mathrm{IU} / \mathrm{kg}$ daily for 8 weeks). The primary end point was reduction of thromboembolic events. The secondary end point was reduction of "early death burden," which they defined as death within 3 months of randomization, citing up to $25 \%$ of patients with advanced pancreas cancer in phase III trials dying within this time. The investigators hypothesized that prophylactic anticoagulation would impact this early mortality. Results from 64 patients in the control arm (61\% with metastatic disease) and 59 patients in the gemcitabine plus dalteparin arm (44\% with metastatic disease) showed thrombosis rates of $25 \%$ and $3.5 \%$ over the first 100 days, and $31 \%$ and $12 \%$ overall, respectively. ${ }^{77}$ The rate of lethal thrombosis and sudden death was $0 \%$ in the dalteparin arm versus $9 \%$ in the control arm $(P=.028)$, but the early death burden was $7 \%$ versus $11 \%$, respectively $(P=.62)$. No difference was seen in overall survival. The investigators therefore 
Epstein and O’Reilly

concluded that the primary end point of thrombosis reduction was met, and a reduction in lethal thrombosis occurred with dalteparin. Despite the relatively small trial size, final results of the trial are anticipated.

Recently, the results from CONKO-004 were reported in abstract form. ${ }^{79}$ In this multicenter prospective randomized phase III trial of chemotherapy with or without primary prophylaxis enoxaparin (1 mg/kg daily for 3 months, followed by $40 \mathrm{mg}$ daily), the investigators accrued 312 patients with advanced pancreas cancer. The primary end point was reduction in symptomatic thrombosis, and secondary end points included toxicity, time to progression, and overall survival. The intention-to-treat analysis showed a significant decrease in symptomatic thrombosis after 3 months $(9.9 \%$ in the chemotherapy alone arm vs. $1.3 \%$ in the enoxaparin arm) and 12 months $(15.1 \%$ in the chemotherapy alone arm vs. $5.0 \%$ in the enoxaparin arm). No significant differences were seen in major bleeding events between the arms. Over a median follow up of 45 months, neither time to progression (5.4 vs. 5.0 months; $P=.941)$ nor overall survival ( 8.0 vs. 8.3 months; $P=.501$ ) were significantly different between the chemotherapy alone and enoxaparin groups, respectively. However, this trial closed early after a data and safety monitoring committee decision confirming the early significant thrombosis reduction, and is therefore underpowered to observe a survival benefit between the arms.

\section{Unreported Trials}

A randomized controlled multicenter study (ClinicalTrials.gov identifier: NCT00031837) has completed accrual of 400 patients with advanced pancreas cancer receiving gemcitabine and is investigating the primary end point of quality of life, wherein patients receive primary prophylaxis dalteparin or placebo in addition to chemotherapy. Secondary end points include overall survival, frequency of symptomatic thrombosis, treatment complications, and safety. Trial NCT00662688 is a 4-arm randomized trial examining the effect of primary prophylaxis dalteparin on the thrombosis rate in patients with metastatic pancreas cancer receiving chemotherapy (gemcitabine with or without capecitabine). Trial NCT00966277 is a randomized protocol with details similar to those of NCT00662688, although with investigator choice of chemotherapy. NCT00426127 was a nonrandomized phase II trial of docetaxel, liposomal doxorubicin, and primary prophylaxis enoxaparin in patients with advanced pancreas cancer; however, it closed early because of poor accrual for a planned 27 patients.

\section{Conclusions}

Pancreas cancer remains an extraordinarily difficult malignancy to treat, and represents one of the most common, if not the commonest, malignancy associated with thrombosis (Table 4). An understanding of the pathogenic underpinnings of pancreas-related thrombosis has evolved over the past several years, providing opportunities for therapeutic interventions. Thromboses and particularly early thromboses have poor prognostic import. Research has clearly shown the importance of anticoagulation, particularly with low-molecular-weight heparin, after the diagnosis of a thrombosis in a patient with malignancy. As of now, however, prophylactic anticoagulation for patients without known thrombosis is not routinely recommended for patients with advanced pancreas cancer outside of a clinical trial. Data maturation from recently completed trials may add insight, but future trials should examine survival as a primary end point and focus on specific patient

\section{Table 4 Key Points in Pancreas Cancer Thrombosis and Anticoagulation ${ }^{2}$}

- Numerous clinical and molecular factors contribute to thrombogenicity in pancreas cancer.

- The relatively high incidence of thrombosis and its contribution to morbidity and mortality in pancreas cancer calls for vigilance in diagnosis and treatment of these events.

- Superficial vein thrombosis with proximity to the deep venous system should be treated with at least 4 weeks of anticoagulation (category $2 \mathrm{~B}^{87}$ ) unless the thrombosis is catheter-associated and the catheter is removed.

- Deep vein thrombosis, including pulmonary embolism, should be anticoagulated. ${ }^{b}$

- Primary prophylactic anticoagulation of hospitalized patients with pancreas cancer is recommended.

- Primary prophylactic anticoagulation of outpatients with pancreas cancer should be performed only in the context of a clinical trial.

${ }^{a}$ Risk of bleeding must always be considered in the decision to initiate anticoagulation.

${ }^{b}$ Duration of anticoagulation treatment for deep vein thrombosis is indefinite for as long as pancreas cancer is active, and low-molecular-weight heparin is recommended over warfarin. 
Pancreas Cancer and Thrombosis

populations. Additionally, pending investigation in the oncology population, the newer-generation oral anticoagulants may ultimately prove to be an additional option (with greater convenience to patients but likely higher cost) for the secondary and perhaps even primary prophylaxis of thrombosis in select patients. Tailoring therapy or focusing investigations to specific patient subsets, such as those presenting with thrombosis concomitant with their pancreas cancer diagnosis, or with high levels of procoagulant molecules, such as tissue factor, may be a justified area of future study. Speculatively, it is possible that treatment stratification based on thrombosis timing/burden in pancreas adenocarcinoma may be entertained going forward.

\section{Acknowledgments}

Special thanks to Isabel Sulimanoff from Library Services at Memorial Sloan-Kettering Cancer for her invaluable assistance with the development and maintenance of the literature search.

\section{References}

1. Blom JW, Osanto S, Rosendaal FR. High risk of venous thrombosis in patients with pancreatic cancer: a cohort study of 202 patients. Eur J Cancer 2006;42:410-414.

2. Cubilla A, Fitzgerald PJ. Pancreas cancer. I. Duct adenocarcinoma. A clinical-pathologic study of 380 patients. Pathol Annu 1978;13 (Pt 1):241-289.

3. Mandala M, Reni M, Cascinu S, et al. Venous thromboembolism predicts poor prognosis in irresectable pancreatic cancer patients. Ann Oncol 2007;18:1660-1665.

4. Oh SY, Kim JH, Lee KW, et al. Venous thromboembolism in patients with pancreatic adenocarcinoma: lower incidence in Asian ethnicity. Thromb Res 2008;122:485-490.

5. Pinzon R, Drewinko B, Trujillo JM, et al. Pancreatic carcinoma and Trousseau's syndrome: experience at a large cancer center. J Clin Oncol 1986;4:509-514.

6. Mitry E, Taleb-Fayad R, Deschamps A, et al. Risk of venous thrombosis in patients with pancreatic adenocarcinoma. Gastroenterol Clin Biol 2007;31:1139-1142.

7. Sgouros J, Maraveyas A. Excess premature (3-month) mortality in advanced pancreatic cancer could be related to fatal vascular thromboembolic events. A hypothesis based on a systematic review of phase III chemotherapy studies in advanced pancreatic cancer. Acta Oncologica 2008;47:337-346.

8. Sorensen HT, Mellemkjaer L, Olsen JH, Baron JA. Prognosis of cancers associated with venous thromboembolism. N Engl J Med 2000;343:1846-1850.

9. Mandala M, Labianca R, Agnelli G, et al. Multicenter, prospective, case-control, observational study on the influence of venous thromboembolism on patient outcome [abstract]. J Clin Oncol 2011;29(Suppl):Abstract 1554.
10. Piccioli A, Falanga A, Prandoni P. Anticoagulants and cancer survival. Semin Thromb Hemost 2006;32:810-813.

11. Zacharski LR, Lee AY. Heparin as an anticancer therapeutic. Expert Opin Investig Drugs 2008;17:1029-1037.

12. Trousseau A. Phlegmasia alba dolens. Clinique Medicale de l'HotelDieu de Paris, 2nd ed. Paris, France: The Sydenham Society; 1865: 654-712.

13. Ay C, Dunkler D, Marosi C, et al. Prediction of venous thromboembolism in cancer patients. Blood 2010;116:5377-5382.

14. Khorana AA, Kuderer NM, Culakova E, et al. Development and validation of a predictive model for chemotherapy-associated thrombosis. Blood 2008;111:4902-4907.

15. Louzada L, Lazo-Langner A, Dao V, et al. Development of a clinical prediction rule for risk stratification of recurrent venous thromboembolism in patients with cancer-associated venous thromboembolism [abstract]. Presented at the 53rd ASH Annual Meeting and Exposition; December 10-13, 2011; San Diego, California. Abstract 475.

16. Vemulapalli S, Chintala L, Tsimberidou AM, et al. Clinical outcomes and factors predicting development of venous thromboembolic complications in patients with advanced refractory cancer in a phase I clinic: the M. D. Anderson Cancer Center experience. Am J Hematol 2009;84:408-413.

17. Ay C, Dunkler D, Marosi C, et al. Prediction of venous thromboembolism in cancer patients. Blood 2010;116:5377-5382.

18. Khorana AA, Francis CW, Culakova E, et al. Thromboembolism in hospitalized neutropenic cancer patients. J Clin Oncol 2006;24:484-490.

19. Simanek R, Vormittag R, Ay C, et al. High platelet count associated with venous thromboembolism in cancer patients: results from the Vienna Cancer and Thrombosis Study (CATS). J Thromb Haemost 2010;8:114-120.

20. Li Z, Webb WB, Mao J, et al. Role of hypoalbuminemia in the development of venous thromboembolism in cancer chemotherapy patients [abstract]. J Clin Oncol 2011;29(Suppl):Abstract 9032.

21. Greenblatt DY, Wan Y, Winslo ER, et al. Body mass index is associated with morbidity after pancreatic resection: results from the ACS-NSQIP. Ann Surg Oncol 2011;18:S118.

22. Shukla A, Shukla S, Zhou X, et al. Association of ABO blood type A and stage IV disease with venous thromboembolism in pancreatic cancer patients [abstract]. J Clin Oncol 2010;28:Abstract e14529.

23. Ay C, Vormittag R, Dunkler D, et al. D-dimer and prothrombin fragment $1+2$ predict venous thromboembolism in patients with cancer: results from the Vienna Cancer and Thrombosis Study. J Clin Oncol 2009;27:4124-4129.

24. Ay C, Simanek R, Vormittag R, et al. High plasma levels of soluble $\mathrm{P}$-selectin are predictive of venous thromboembolism in cancer patients: results from the Vienna Cancer and Thrombosis Study (CATS). Blood 2008;112:2703-2708.

25. Ay C, Dunkler D, Simanek R, et al. Prediction of venous thromboembolism in patients with cancer by measuring thrombin generation: results from the Vienna Cancer and Thrombosis Study. J Clin Oncol 2011;29:2099-2103.

26. Cushman M. Epidemiology and risk factors for venous thrombosis. Semin Hematol 2007;44:62-69.

27. Khorana AA, Connolly GC. Assessing risk of venous thromboembolism in the patient with cancer. J Clin Oncol 2009;27:4839-4847. 
Epstein and O’Reilly

28. Shivakumar SP, Anderson DR, Couban S. Catheter-associated thrombosis in patients with malignancy. J Clin Oncol 2009;27:4858-4864.

29. Bennett CL, Silver SM, Djulbegovic B, et al. Venous thromboembolism and mortality associated with recombinant erythropoietin and darbepoetin administration for the treatment of cancer-associated anemia. JAMA 2008;299:914-924.

30. Lippi G, Franchini M, Favaloro EJ. Thrombotic complications of erythropoiesis-stimulating agents. Semin Thromb Hemost 2010;36:537-549.

31. Bligh M, Sehdev S, Kuruvilla P. Venous thrombosis in the setting of metastatic pancreatic carcinoma. Pathophysiol Haemost Thromb 2010;37:A104.

32. Dasanu CA. Gemcitabine: vascular toxicity and prothrombotic potential. Expert Opin Drug Saf 2008;7:703-716.

33. Moore R, Adel N, Bhutani M, et al. Cisplatin-based chemotherapy is associated with an unacceptably high incidence of thromboembolic events: a large retrospective analysis [abstract]. Presented at the 51st ASH Annual Meeting and Exhibition; December 5-8, 2009; New Orleans, Louisianna. Abstract 456.

34. Lindahl AK, Boffa MC, Abildgaard U. Increased plasma thrombomodulin in cancer patients. Thromb Haemost 1993;69:112-114.

35. Heinmoller E, Schropp T, Kisker O, et al. Tumor cell-induced platelet aggregation in vitro by human pancreatic cancer cell lines. Scand J Gastroenterol 1995;30:1008-1016.

36. Haas SL, Jesnowski R, Steiner M, et al. Expression of tissue factor in pancreatic adenocarcinoma is associated with activation of coagulation. World J Gastroenterol 2006;12:4843-4849.

37. Andren-Sandberg A, Lecander I, Martinsson G, Astedt B. Peaks in plasma plasminogen activator inhibitor-1 concentration may explain thrombotic events in cases of pancreatic carcinoma. Cancer 1992;69:2884-2887.

38. Poruk KE, Firpo MA, Huerter LM, et al. Serum platelet factor 4 is an independent predictor of survival and venous thromboembolism in patients with pancreatic adenocarcinoma. Cancer Epidemiol Biomarkers Prev 2010;19:2605-2610.

39. Thomas GM, Panicot-Dubois L, Lacroix R, et al. Cancer cellderived microparticles bearing P-selectin glycoprotein ligand 1 accelerate thrombus formation in vivo. J Exp Med 2009;206:19131927.

40. Mirshahi S, Soria C, Chidiac J, et al. Plasma soluble fibrin level, a clinically useful predictor of thrombosis in cancer patients? J Thromb Haemost 2009;7:797-798.

41. Kurer MA. Protein and mRNA expression of tissue factor pathway inhibitor-1 (TFPI-1) in breast, pancreatic and colorectal cancer cells. Mol Biol Rep 2007;34:221-224.

42. Silberberg JM, Gordon S, Zucker S. Identification of tissue factor in two human pancreatic cancer cell lines. Cancer Res 1989;49:54435447.

43. Delluc A, Rousseau A, Delluc C, et al. Venous thromboembolism in patients with pancreatic cancer: implications of circulating tissue factor. Blood Coagul Fibrinolysis 2011;22:295-300.

44. Davila M, Amirkhosravi A, Coll E, et al. Tissue factor-bearing microparticles derived from tumor cells: impact on coagulation activation. J Thromb Haemost 2008;6:1517-1524.

45. Yates KR, Welsh J, Echrish HH, et al. Pancreatic cancer cell and microparticle procoagulant surface characterization: involvement of membrane-expressed tissue factor, phosphatidylserine and phosphatidylethanolamine. Blood Coagul Fibrinolysis 2011;22:680-687.

46. Zwicker JI, Liebman HA, Neuberg D, et al. Tumor-derived tissue factor-bearing microparticles are associated with venous thromboembolic events in malignancy. Clin Cancer Res 2009; 15:6830-6840.

47. AklEA, van Doormaal FF, Barba M, et al. Parenteral anticoagulation may prolong the survival of patients with limited small cell lung cancer: a Cochrane systematic review. J Exp Clin Cancer Res 2008;27:4.

48. Lee AY, Levine MN, Baker RI, et al. Low-molecular-weight heparin versus a coumarin for the prevention of recurrent venous thromboembolism in patients with cancer. $\mathrm{N}$ Engl J Med 2003;349:146-153.

49. Lee AY, Rickles FR, Julian JA, et al. Randomized comparison of low molecular weight heparin and coumarin derivatives on the survival of patients with cancer and venous thromboembolism. J Clin Oncol 2005;23:2123-2129.

50. Siragusa S, Cosmi B, Piovella F, et al. Low-molecular-weight heparins and unfractionated heparin in the treatment of patients with acute venous thromboembolism: results of a meta-analysis. Am J Med 1996;100:269-277.

51. Gould MK, Dembitzer AD, Doyle RL, et al. Low-molecular-weight heparins compared with unfractionated heparin for treatment of acute deep venous thrombosis. A meta-analysis of randomized, controlled trials. Ann Intern Med 1999;130:800-809.

52. Hettiarachchi RJ, Smorenburg SM, Ginsberg J, et al. Do heparins do more than just treat thrombosis? The influence of heparins on cancer spread. Thromb Haemost 1999;82:947-952.

53. Dolovich LR, Ginsberg JS, Douketis JD, et al. A meta-analysis comparing low-molecular-weight heparins with unfractionated heparin in the treatment of venous thromboembolism: examining some unanswered questions regarding location of treatment, product type, and dosing frequency. Arch Intern Med 2000;160:181-188.

54. Zacharski LR, Henderson WG, Rickles FR, et al. Effect of warfarin anticoagulation on survival in carcinoma of the lung, colon, head and neck, and prostate. Final report of VA Cooperative Study \#75. Cancer 1984;53:2046-2052.

55. Chahinian AP, Propert KJ, Ware JH, et al. A randomized trial of anticoagulation with warfarin and of alternating chemotherapy in extensive small-cell lung cancer by the Cancer and Leukemia Group B. J Clin Oncol 1989;7:993-1002.

56. Lebeau B, Chastang C, Brechot JM, et al. Subcutaneous heparin treatment increases survival in small cell lung cancer. "Petites Cellules" Group. Cancer 1994;74:38-45.

57. Maurer LH, Herndon JE II, Hollis DR, et al. Randomized trial of chemotherapy and radiation therapy with or without warfarin for limited-stage small-cell lung cancer: a Cancer and Leukemia Group B study. J Clin Oncol 1997;15:3378-3387.

58. Altinbas M, Coskun HS, Er O, et al. A randomized clinical trial of combination chemotherapy with and without low-molecularweight heparin in small cell lung cancer. J Thromb Haemost 2004;2:1266-1271.

59. Kakkar AK, Levine MN, Kadziola Z, et al. Low molecular weight heparin, therapy with dalteparin, and survival in advanced cancer: the fragmin advanced malignancy outcome study (FAMOUS). J Clin Oncol 2004;22:1944-1948.

60. Klerk CP, Smorenburg SM, Otten HM, et al. The effect of low molecular weight heparin on survival in patients with advanced malignancy. J Clin Oncol 2005;23:2130-2135. 
Pancreas Cancer and Thrombosis

61. Sideras K, Schaefer PL, Okuno SH, et al. Low-molecular-weight heparin in patients with advanced cancer: a phase 3 clinical trial. Mayo Clin Proc 2006;81:758-767.

62. Kuderer N, Ortel T, Khorana A, et al. Low molecular weight heparin thromboprophylaxis in ambulatory cancer patients: a systematic review and meta-analysis of randomized controlled trials [abstract]. Blood 2009;114:Abstract 490.

63. Kuderer NM, Khorana AA, Lyman GH, Francis CW. A metaanalysis and systematic review of the efficacy and safety of anticoagulants as cancer treatment: impact on survival and bleeding complications. Cancer 2007;110:1149-1161.

64. Lazo-Langner A, Goss GD, Spaans JN, Rodger MA. The effect of low-molecular-weight heparin on cancer survival. A systematic review and meta-analysis of randomized trials. J Thromb Haemost 2007;5:729-737.

65. Khorana AA, Streiff MB, Farge D, et al. Venous thromboembolism prophylaxis and treatment in cancer: a consensus statement of major guidelines panels and call to action. J Clin Oncol 2009;27:4919-4926.

66. Giever TA, Adwan KM, Cheng Y, Atallah EL. Comparison of venous thromboemboli (VTE) incidence in cancer patients who are on statin therapy versus those not on statin therapy [abstract]. J Clin Oncol 2010;28:Abstract 9033.

67. Khemasuwan D, DiVietro ML, Tangdhanakanond K, et al. Statins decrease the occurrence of venous thromboembolism in patients with cancer. Am J Med 2010;123:60-65.

68. Sproul E. Carcinoma and venous thrombosis: the frequency of association of carcinoma in the body and tail of the pancreas with multiple venous thrombosis. Am J Cancer 1938:566-585.

69. Ogren M, Bergqvist $\mathrm{D}$, Wahlander $\mathrm{K}$, et al. Trousseau's syndrome - what is the evidence? A population-based autopsy study. Thromb Haemost 2006;95:541-545.

70. Mikal S, Campbell AJ. Carcinoma of the pancreas. Diagnostic and operative criteria based on one hundred consecutive autopsies. Surgery 1950;28:963-969.

71. Thompson CM, Rodgers LR. Analysis of the autopsy records of 157 cases of carcinoma of the pancreas with particular reference to the incidence of thromboembolism. Am J Med Sci 1952;223:469-478.

72. Soederstroem J, Bjersing L. Prevalence of thrombi in carcinoma of the pancreas. Acta Pathol Microbiol Scand 1963;59:443-446.

73. Mao C, Domenico DR, Kim K, et al. Observations on the developmental patterns and the consequences of pancreatic exocrine adenocarcinoma. Findings of 154 autopsies. Arch Surg 1995;130:125-134.

74. Lowe WC, Palmer ED. Carcinoma of the pancreas. An analysis of 100 patients. Am J Gastroenterol 1967;47:412-420.

75. Epstein AS, Soff GA, Capanu M, et al. Analysis of incidence and clinical outcomes in patients with thromboembolic events and invasive exocrine pancreatic cancer. Cancer, in press.
76. Shaib W, Deng Y, Zilterman D, et al. Assessing risk and mortality of venous thromboembolism in pancreatic cancer patients. Anticancer Res 2010;30:4261-4264.

77. Maraveyas A, Waters J, Roy R, et al. Gemcitabine with or without prophylactic weight-adjusted dalteparin in patients with advanced or metastatic pancreatic cancer (APC): a multicentre, randomised phase IIB trial (the UK FRAGEM study)[abstract]. Eur J Cancer 2009;7:362:Abstract 6503.

78. Agnelli G, Gussoni G, Bianchini C, et al. Nadroparin for the prevention of thromboembolic events in ambulatory patients with metastatic or locally advanced solid cancer receiving chemotherapy: a randomised, placebo-controlled, double-blind study. Lancet Oncol 2009;10:943-949.

79. Riess H, Pelzer U, Opitz B, et al. A prospective, randomized trial of simultaneous pancreatic cancer treatment with enoxaparin and chemotherapy: final results of the CONKO-004 trial [abstract]. J Clin Oncol 2010;28(Suppl):Abstract 4033.

80. Icli F, Akbulut H, Utkan G, et al. Low molecular weight heparin (LMWH) increases the efficacy of cisplatinum plus gemcitabine combination in advanced pancreatic cancer. J Surg Oncol 2007;95:507-512.

81. von Delius S, Ayvaz M, Wagenpfeil S, et al. Effect of low-molecularweight heparin on survival in patients with advanced pancreatic adenocarcinoma. Thromb Haemost 2007;98:434-439.

82. van Doormaal FF, Di Nisio M, Otten HM, et al. Randomized trial of the effect of the low molecular weight heparin nadroparin on survival in patients with cancer. J Clin Oncol 2011;29:2071-2076.

83. Louzada ML, Majeed H, Wells PS. Efficacy of low- molecularweight- heparin versus vitamin $\mathrm{K}$ antagonists for long term treatment of cancer-associated venous thromboembolism in adults: a systematic review of randomized controlled trials. Thromb Res 2009;123:837-844.

84. Price LH, Nguyen MB, Picozzi VJ, Kozarek RA. Portal vein thrombosis in pancreatic cancer: natural history, risk factors, and implications for patient management [abstract]. Presented at the 2010 Gastrointestinal Cancers Symposium; January 22-24, 2010; Orlando, Florida. Abstract 143.

85. Nakchbandi W, Müller H, Singer MV, et al. Prospective study on warfarin and regional chemotherapy in patients with pancreatic carcinoma. J Gastrointestin Liver Dis 2008;17:285-290.

86. Loprinzi CL, Kugler JW, Sloan JA, et al. Randomized comparison of megestrol acetate versus dexamethasone versus fluoxymesterone for the treatment of cancer anorexia/cachexia. J Clin Oncol 1999;17:3299-3306.

87. Streiff MB, Bockenstedt PL, Cataland SR, et al. NCCN Clinical Practice Guidelines in Oncology for Venous Thromboembolic Disease, version 2.2011. Available at: NCCN.org. Accessed April $18,2012$. 


\section{CME Activity: Thromboembolism in Pancreatic Cancer}

To obtain credit, you should first read the journal article. After reading the article, you should be able to answer the following, related, multiplechoice questions. To complete the questions (with a minimum $70 \%$ passing score) and earn continuing medical education $(\mathrm{CME})$ credit, please go to www. medscape.org/journal/jnccn.

Credit cannot be obtained for tests completed on paper, although you may use the worksheet below to keep a record of your answers. You must be a registered user on Medscape.org. If you are not registered on Medscape.org, please click on the New Users: Free Registration link on the left hand side of the website to register.

Only one answer is correct for each question. Once you successfully answer all post-test questions you will be able to view and/or print your certificate.
For questions regarding the content of this activity, contact the accredited provider, CME@medscape.net. For technical assistance, contact CME@webmd.net.

American Medical Association's Physician's Recognition Award (AMA PRA) credits are accepted in the U.S. as evidence of participation in CME activities. For further information on this award, please refer to http:/www.ama-assn.org/ama/pub/ category/2922.html. The AMA has determined that physicians not licensed in the U.S. who participate in this CME activity are eligible for AMA PRA Category 1 Credits $^{\mathrm{TM}}$. Through agreements that the AMA has made with agencies in some countries, AMA PRA credit may be acceptable as evidence of participation in CME activities. If you are not licensed in the U.S., please complete the questions online, print the AMA PRA CME credit certificate, and present it to your national medical association for review.

1. You are seeing a 66-year-old man with a recent diagnosis of pancreatic cancer. You know that this diagnosis places him at high risk for thromboembolic events. Which of the following factors is most significant in promoting a higher risk of thromboembolism among patients with pancreatic cancer?
A Non-A blood type
B. A low or normal platelet count
C. Normal levels of D-dimer
D. The use of erythropoietin-stimulating agents

2. You consider initiating primary prophylaxis against thromboembolism for this patient. What is the general recommendation regarding this practice in the setting of pancreatic cancer?
A. It is not part of routine care
B. It should be initiated only among patients over the age of 65 years
C. It should be initiated only among women
D. It is now considered to be the standard of care

3. The patient develops a lower extremity deep venous thrombosis. Which of the following agents is most preferred for management of thrombosis?
A. Warfarin
B. Dabigatran
C. Low-molecular-weight heparin
D. Unfractionated heparin

4. You initiate therapy with the recommended treatment. Based on available prospective studies, which of the following outcomes is most likely with antithrombotic therapy?
A. A higher risk of bleeding
B. A lower risk of thromboembolic events
C. A reduction in cancer progression
D. A higher rate of overall survival

\section{Activity Evaluation}

1. The activity supported the learning objectives. $\begin{array}{rrrrr}\text { Strongly Disagree } & & \text { Strongly Agree } \\ 1 & 2 & 3 & 4 & 5\end{array}$

2. The material was organized clearly for learning to occur.

3. The content learned from this activity will impact my practice.

Strongly Disagree

$\begin{array}{lllll}1 & 2 & 3 & 4 & 5\end{array}$

4. The activity was presented objectively and free of commercial bias.
Strongly Disagree
123
Strongly Agree
Strongly Disagree

$\begin{array}{lllrr}1 & 2 & 3 & 4 & 5\end{array}$

To obtain credit, visit Medscape online at http://www.medscape.org/journal/jnccn. 